\title{
The Semantic Knowledge-base of Contemporary Chinese and its Applications in WSD*
}

\author{
Hui Wang \\ Shiwen Yu \\ Institute of Computational Linguistics Institute of Computational Linguistics \\ Peking University \\ Peking University \\ Beijing 100871, China \\ Beijing 100871, China \\ whuiepku.edu.cn \\ yusw@pku.edu.cn
}

\begin{abstract}
The Semantic Knowledge-base of Contemporary Chinese (SKCC) is a large scale Chinese semantic resource developed by the Institute of Computational Linguistics of Peking University. It provides a large amount of semantic information such as semantic hierarchy and collocation features for 66,539 Chinese words and their English counterparts. Its POS and semantic classification represent the latest progress in Chinese linguistics and language engineering. The descriptions of semantic attributes are fairly thorough, comprehensive and authoritative. The paper introduces the outline of SKCC, and indicates that it is effective for word sense disambiguation in MT applications and is likely to be important for general Chinese language processing.
\end{abstract}

Key words: Semantic knowledge-base, lexical semantic, computational lexicography, word sense disambiguation

(WSD), Chinese language processing

\section{Introduction}

Semantic resources play an important role in many areas of Natural Language Processing (NLP). The Institute of Computational Linguistics (ICL) of
Peking University has been engaged in research and development of the Semantic Knowledge-base of Contemporary Chinese (SKCC) in the last eight years. This lexicon-building project was a collaboration with the Institute of Computing Technology, Chinese Academy of Sciences during 1994-1998, and resulted in a machine-readable bilingual lexicon suitable for use with Machine Translation applications, which contained a fairly complete characterization of the semantic classification, valence specifications and collocation properties for 49 thousands Chinese words and their English counterparts (Wang Hui, 1998).

Since 2001, the further development of SKCC has been co-conducted by ICL and Chinese Department of Peking University. At present, SKCC has made great progress. Not only is the scale extended to 66,539 entries, but also the quality has been immensely improved. The semantic classification in the updated edition of SKCC is the embodiment of the very latest progress in Chinese linguistics and language engineering, while the semantic descriptions are comprehensive and thorough. It can provide rich lexical semantic information for various NLP applications.

\section{Outline of SKCC}

\subsection{Scale and Structure}

SKCC consists of one general database and six sub-databases. The general database contains shared attributes of all the 66,539 entries, while the sub-databases provide detailed descriptions of the

\footnotetext{
${ }^{*}$ Supported by China National Fundamental Research Program (973) (PN: G1998030507-4).
} 
distinctive semantic attributes associated with the parts of speech (POS). For example, the verb database has 16 attribute fields, noun database and adjective database has 15 attribute fields respectively.

\begin{tabular}{|l|c|c|l|}
\hline $\begin{array}{c}\text { Database } \\
\text { Name }\end{array}$ & Entries & $\begin{array}{c}\text { Attribute } \\
\text { fields }\end{array}$ & $\begin{array}{c}\text { Attribute } \\
\text { value }\end{array}$ \\
\hline nouns & 38,478 & 15 & 5 \\
\hline verbs & 21,142 & 16 & 3 \\
\hline adjective & 5,577 & 15 & 8 \\
\hline pronouns & 236 & 15 & 3 \\
\hline adverbs & 997 & 11 & 1 \\
\hline numerals & 109 & 11 & 1 \\
\hline General & 66,539 & 8 & 5 \\
\hline Total & 133,07 & $\mathbf{9 1}$ & $\mathbf{1}$ \\
\hline
\end{tabular}

Table 1 Scale of SKCC

All of the six sub-databases can be linked to the general database through four key fields, namely ENTRY, POS, HOMOMORPHISM and SENSE. As a result, the son knots can inherit all information from their father knots (Figure 1).

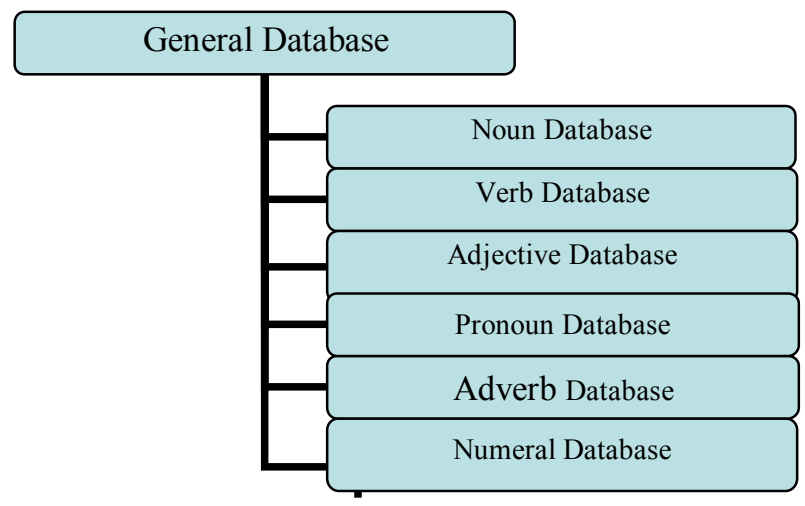

Figure 1 Main structure of SKCC

\subsection{Semantic Hierarchy}

One of the most outstanding characteristics of SKCC is that its semantic hierarchy is based on grammatical analysis, rather than merely on general knowledge (as illustrated in Figure 2 below). This classification system represents the latest progress in Chinese semantics. It is very useful for NLP applications(Zhan Weidong, 1997), as well as compatible with various semantic resources, such as Wordnet (Christiane Fellbaum. 1998), Chinese concept dictionary (CCD)( Yu Jiangsheng, 2002), HowNet(Dong Zhendong, 2000) etc. Currently, the classification of all of the 66,539 entries has already been completed.
( 1 ) Verbs

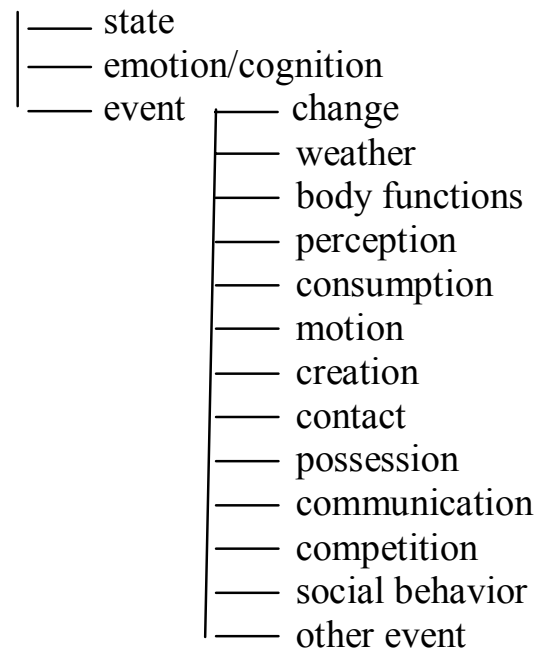

( 2 ) Adjectives

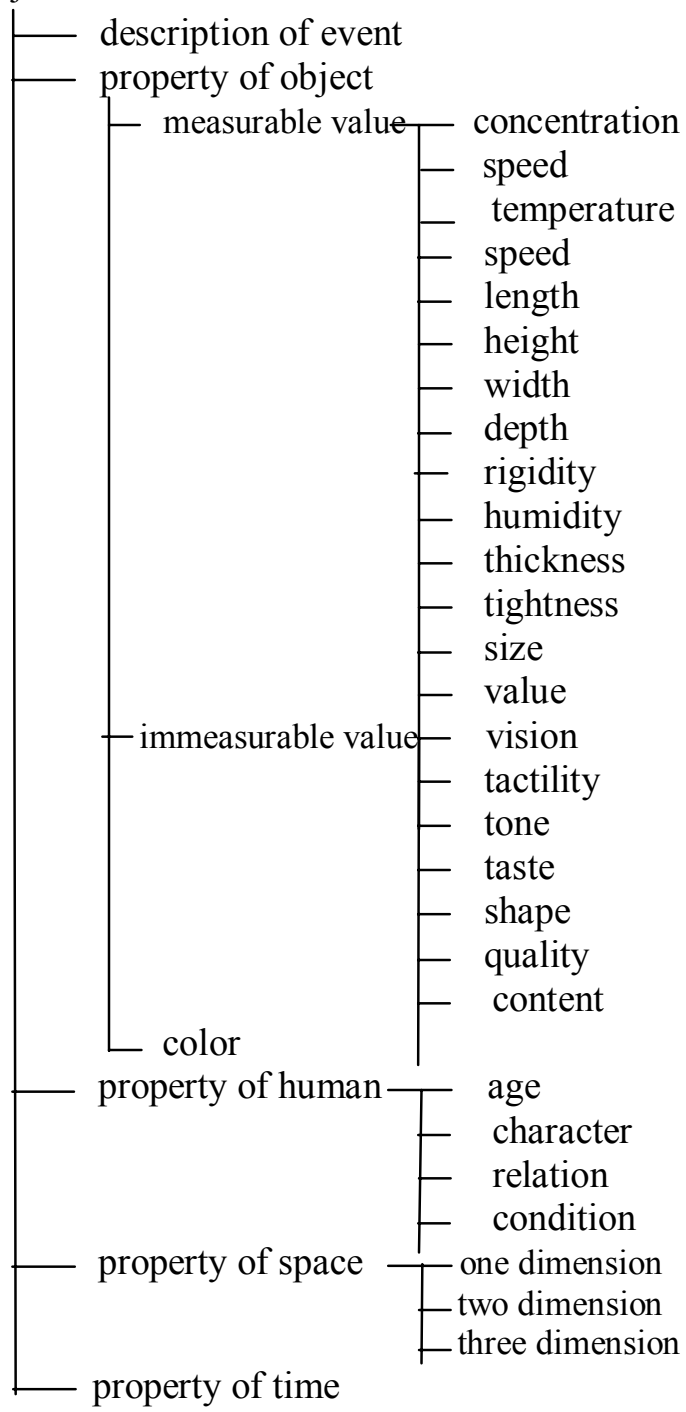




\section{(3) Nouns}

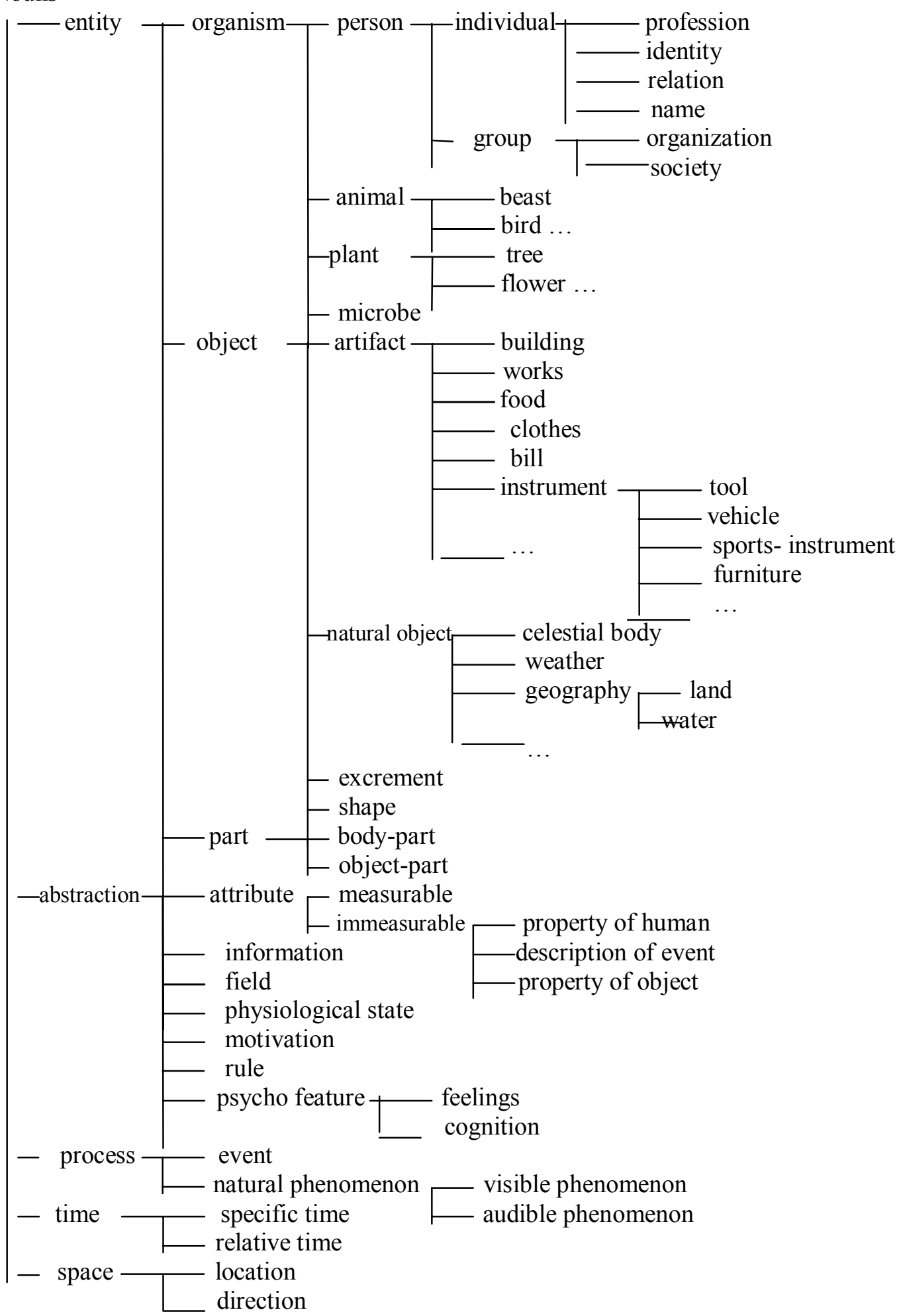


( 4 ) adverbs

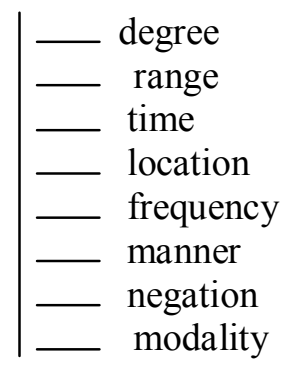

( 5 ) numerals

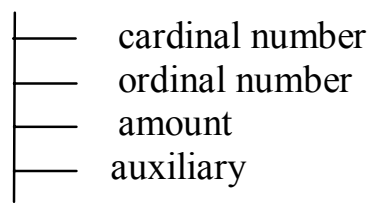

Figure 2 Semantic hierarchy in SKCC

\subsection{Comprehensive Semantic Descriptions}

There is close correlation between lexical meaning and its distribution. Oriented to MT and IR, one aim of SKCC is to provide detailed semantic description and collocation behavior that in many cases is likely to be uniquely associated with a single sense. For example, following attribute fields have been filled with values in the verb database (see table 2).

\begin{tabular}{|l|l|}
\hline ENTRY & $\begin{array}{l}\text { Commonly used Chinese } \\
\text { word or idiom phrase }\end{array}$ \\
\hline PRONUNCIATION & $\begin{array}{l}\text { Chinese Pinyin with tones } \\
\text { such as "chi3zi5" for “尺 } \\
\text { 子"(ruler) }\end{array}$ \\
\hline $\begin{array}{l}\text { PART OF } \\
\text { SPEECH }\end{array}$ & $\begin{array}{l}\text { POS tagging of per word or } \\
\text { idiom }\end{array}$ \\
\hline $\begin{array}{l}\text { SUB- } \\
\text { CATEGORY }\end{array}$ & $\begin{array}{l}\text { Sub-category tagging of per } \\
\text { word or idiom }\end{array}$ \\
\hline POSs & $\begin{array}{l}\text { All POS tagging of per } \\
\text { word }\end{array}$ \\
\hline HOMOMORPHISM & Homograph number \\
\hline SENSE & $\begin{array}{l}\text { Sense number of per } \\
\text { polysemous word }\end{array}$ \\
\hline DEFINITION & Sense definition \\
\hline $\begin{array}{l}\text { SEMANTIC } \\
\text { CATEGORY }\end{array}$ & $\begin{array}{l}\text { Semantic categories of per } \\
\text { word or idiom. A word can } \\
\text { be tagged with two or more } \\
\text { semantic categories. For }\end{array}$ \\
\hline
\end{tabular}

\begin{tabular}{|l|l|}
\hline & $\begin{array}{l}\text { instance, the noun “青菜” } \\
\text { (greengrocery) belong to } \\
\text { "plant | food" categories. }\end{array}$ \\
\hline VALENCE & $\begin{array}{l}\text { Valence number of each } \\
\text { entry. For example, “咳 } \\
\text { 嗽”(cough) is a one-valence } \\
\text { verb, while “吃”(eat) is a } \\
\text { two-valence one, } \\
\text { “给”(give) is three-valence. }\end{array}$ \\
\hline AGENT & Actor of action or motion. \\
\hline OBJECT & $\begin{array}{l}\text { Object of action. } \\
\text { Beneficiary or suffer of } \\
\text { DATIVE }\end{array}$ \\
\hline TRANSLATION & $\begin{array}{l}\text { English counterpart of per } \\
\text { word or idiom. }\end{array}$ \\
\hline ECAT & $\begin{array}{l}\text { POS tagging of per English } \\
\text { word or phrase. }\end{array}$ \\
\hline ILLUSTRATIONS & $\begin{array}{l}\text { Corpus-derived example } \\
\text { sentences showing authen- } \\
\text { tic contexts of a word or } \\
\text { idiom. }\end{array}$ \\
\hline
\end{tabular}

Table 2 Semantic attributes in the verb database of SKCC

To sum up, the above attributes fall into five kinds of information below:

(1) Basic information of entry, such as vocabulary item, part of speech, sub-category, homograph and pronunciation;

(2) Descriptions of word meaning, including sense number, definition, and semantic categories;

(3) Semantic valence, thematic roles and combinatorial properties for per words; this is the most important part of SKCC and especially useful for WSD and lexical semantics research;

(4) English translation and its POS tagging. If a Chinese word has two or more English counterparts, it will be regarded as different entries respectively, and the collocation information will also be given in relevant fields. This can significantly improve the quality of Chinese-English MT system.

(5) Corpus-derived authentic examples of a word in context, showing how it is used, how phrases are formed around it, and so on.

\section{Application in WSD}

As a large-scale lexical knowledge base, SKCC combines the features of many of the other re- 
sources commonly exploited in NLP work: it includes definitions and English translations for individual senses of words within it, as in a bilingual dictionary; it organizes lexical concepts into a conceptual hierarchy, like a thesaurus; and it includes other links among words according to several semantic relations, including semantic role, collocation information etc. As such it currently provides the broadest set of lexical information in a single resource. The kind of information recorded and made available through SKCC is of a type usable for various NLP applications, including machine translation, automatic abstraction, information retrieval, hypertext navigation, thematic analysis, and text processing.

In this section, we shall focus on the automatic disambiguation of Chinese word senses involving SKCC since it is most troublesome, and essential for all the above NLP applications (Ide, 1998).

\subsection{Determination of the polysemous words and homographs}

In general terms, word sense disambiguation (WSD) task necessarily involves two steps: (1) the determination of all the polysemous words and homographs in the text or discourse; and (2) a means to assign each occurrence of a word to the appropriate sense.

Step (1) can be easily accomplished by reliance on SKCC. Firstly, each entry denotes one single sense of per word in SKCC. Thus, if a word has two or more senses, it will be regard as different entries, and the "SENSE" field will be filled with different number (as “菜” in table 3).

\begin{tabular}{||c|c|c||}
\hline ENTRY & 菜 $^{1}$ & 菜 $^{2}$ \\
\hline POS & $\mathrm{n}$ & $\mathrm{n}$ \\
\hline SENSE & 1 & 2 \\
\hline DEFINITION & vegetable & $\begin{array}{l}\text { cooked vege- } \\
\text { table, egg, } \\
\text { fish, meat...etc }\end{array}$ \\
\hline TRANSLATION & vegetable & dish \\
\hline ILLUSTRATIONS & $\begin{array}{c}\text { 种 } \\
\text { grow } \\
\text { vegetables } \\
\text { 野 } \\
\text { potherb }\end{array}$ & $\begin{array}{c}\text { 荤 } ~ \\
\text { meat or fish } \\
\text { 四 } \sim \text { - 汤 } \\
\text { four dishes } \\
\text { and a bowl } \\
\text { of soup }\end{array}$ \\
\hline \hline
\end{tabular}

Table 3 Two senses of Chinese noun “菜”
Secondly, SKCC marked all of the homographs in "HOMOMORPHISM" field, such as two verbs “看” with different pronunciation in table 4.

\begin{tabular}{||c|c|c||}
\hline ENTRY & 看 $^{1}$ & 看 $^{2}$ \\
\hline PRONUNCIATION & Kan4 & Kan1 \\
\hline HOMOMORPHISM & A & B \\
\hline DEFINITION & $\begin{array}{c}\text { see; } \\
\text { watch; } \\
\text { look at }\end{array}$ & $\begin{array}{l}\text { look after; } \\
\text { take care of }\end{array}$ \\
\hline TRANSLATION & see & look after \\
\hline
\end{tabular}

Table 4 Homographs in SKCC

Therefore, if either of the "SENSE" and "HOMOMORPHISM" fields is filled with value in SKCC, the entry must be a polysemous word or homograph.

\subsection{WSD based on semantic categories}

The senses of most Chinese polysemous words and homographs belong to different semantic categories, and have different syntagmatic features in context (Wang Hui, 2002). SKCC gives detailed description of such information in "AGENT" and/or "OBJECT" fields as illustrated in table 5 below.

\begin{tabular}{|c|c|c|}
\hline ENTRY & 清淡 ${ }^{1}$ & 清淡 $^{2}$ \\
\hline POS & $\mathrm{a}$ & $\mathrm{a}$ \\
\hline SENSE & 1 & 2 \\
\hline DEFINITION & $\begin{array}{c}\text { (of food, } \\
\text { drink, } \\
\text { smell) } \\
\text { light; } \\
\text { weak }\end{array}$ & $\begin{array}{l}\text { (of business) } \\
\text { slack }\end{array}$ \\
\hline $\begin{array}{l}\text { SEMANTIC } \\
\text { CATEGORY }\end{array}$ & taste & condition \\
\hline AGENT & $\begin{array}{c}\text { food } \mid \text { drink } \mid \\
\text { plant }\end{array}$ & "business" \\
\hline TRANSLATION & light & slack \\
\hline
\end{tabular}

Table 5 Polysemous adjectives in SKCC

Based on the above description, the target word “清淡” in following POS-tagged text can be accurately disambiguated:

[1] 一/m 杯 $/ \mathrm{q}$ 清淡/a 的 $/ \mathrm{u}$ 龙井茶 $/ \mathrm{n}$ A cup of light Longjing tea. 
[2] 农忙时 $/ \mathrm{t}$ 进城/ $/ \mathrm{\text { }}$ 的 $/ \mathrm{u}$ 人 $/ \mathrm{n}$ 不 $/ \mathrm{d}$ 多/ $\mathrm{a}$ ，生意/ $\mathrm{n}$ 比较/d 清淡/a。

When the season is busy, few farmers go to town and the business is rather slack.

In sentence[1], the word modified by “清淡” is the noun"茶”(tea), which is a kind of "drink"; while the word"清淡" in sentence [2] is a predicate of "business". According to the different values in "AGENT" field, it is easy to judge that these two “清淡” belong to two semantic categories, viz. the former is "light", and the latter is "slack".

\subsection{WSD based on collocation information}

As for the polysemous words or homographs belonging to the same semantic category, the difference between them usually manifests at the collocation level. According to a study in cognitive science, people often disambiguate word sense using only a few other words in a given context (frequently only one additional word) ( Choueka, 1983). Thus, the relationships between one word and others can be effectively used to resolve ambiguity. For example, Chinese verb “找” has two senses: one is “寻找” (look for) and the other is “ 退还” (give change). Only when the verb cooccurs with the noun “钱” (money), it can be interpreted as "give change"; Otherwise, it means "look for" (see table 6).

\begin{tabular}{||c|c|c||}
\hline ENTRY & \multicolumn{1}{|c||}{ 找 $^{1}$} & 找 $^{2}$ \\
\hline HOMOMORPHISM & A & B \\
\hline SENSE & 1 & 2 \\
\hline DEFINITION & $\begin{array}{l}\text { look for; } \\
\text { seek try to } \\
\text { find; }\end{array}$ & give change \\
\hline AGENT & person & entity \\
\hline OBJECT & entity & "money" \\
\hline DATIVE & & person \\
\hline TRANSLATION & look for & give change \\
\hline
\end{tabular}

Table 6 Different senses of verb “找”

According to table 6, the verb "找” in sentence [1] below must be "look for", because its object is “人” (person), a kind of "entity"; while “ 找" in sentence [2] has two objects, namely, indirect object “我” (me) and direct object "钱 "(money). Thus, its meaning is "give change".
[1]他们 $/ \mathrm{r}$ 将/d 出去 $/ \mathrm{v}$ 找 $/ \mathrm{v}$ 人 $/ \mathrm{n}$ 。

They will go out to look for $s b$.

[2]售货员 $/ \mathrm{n}$ 还 $/ \mathrm{d}$ 没有 $/ \mathrm{d}$ 找 $/ \mathrm{v}$ 我 $/ \mathrm{r}$ 钱 $/ \mathrm{n}$ 呢

The seller has not given change to me.

By making full use of SKCC and a large scale POS-tagged corpus of Chinese, a multi-levels WSD model is developed and has already been used in a Chinese-English MT application.

\section{Conclusion}

SKCC is a well-structured Chinese-English bilingual semantic resource, as described in the paper, it has more than 66,000 Chinese words and their English counterparts classified, and the accurate description of about 1.5 million attributes further enriched the abundance of lexical semantic knowledge. It not only provides a deductive system of word meaning and valuable semantic knowledge for Chinese language processing, but also has great theoretical significance in lexical semantics and computational lexicography research.

\section{Acknowledgement}

We appreciate all the members participated in SKCC project, especially Prof. Lu Jianming, Dr. Zhan Weidong, Mr. Li Kangnian and Dr. Chang Baobao. The blithesome collaboration with Dr. Ying Chenjin and Mr. Guo qingjian from Chinese Department is memorable for all of us. Lastly, thanks our colleagues and friends for their kindly discussion with the authors.

\section{References}

Choueka, Y. and S. Lusignan, 1983. "A Connectionist Scheme for Modeling Word Sense Disambiguation," Cognition and Brain Theory. 6 (1). pp.89-120.

Christiane Fellbaum. 1998. WordNet: an electronic lexical database. Mass: MIT Press.

Dong Zhendong, Dong Qiang. 200. "Hownet". http:// www.keenage.com.

Ide, Nancy; Jean Véronis. 1998. "Introduction to the Special Issue on Word Sense Disambiguation: The State of the Art", Computational Linguistics. Vol.24, No.1. pp1-40 
Wang Hui, Zhan Weidong, Liu Qun. 1998. "Design of Semantic Dictionary of Modern Chinese". Proceedings from 1998 International Conference on Chinese Information Processing. Beijing: Tsinghua University Press. pp361-367.

Wang Hui. 2002. "Chinese Word Sense Disambiguation in Machine Translation". Proceedings from Chinese National Symposium on Machine Translation. Beijing: Publishing House of Electronics Industry. pp.34-43.

Yu Jiangsheng, Yu Shiwen. 2002. "Structure and Design of CCD". Chinese Information Processing. 16 (4): 12-20.

Zhan Weidong, Liu Qun. 1997. "The important role of semantic classification in ChineseEnglish MT". Language Engineering. Tsinghua University Press. 286-291. 